\title{
Robotic selective thoracic sympathectomy for hyperhidrosis
}

\author{
Farid Gharagozloo \\ Center for Advanced Thoracic Surgery, Global Robotics Institute, Advent Health Celebration, University of Central Florida, \\ Celebration, Florida, FA 34786, USA.
}

Correspondence to: Dr. Farid Gharagozloo, Center for Advanced Thoracic Surgery, Global Robotics Institute, Advent Health Celebration, University of Central Florida, 400 Celebration Place, Celebration, Florida 34786, USA.

E-mail: Gharagozloof@aol.com

\begin{abstract}
How to cite this article: Gharagozloo F. Robotic selective thoracic sympathectomy for hyperhidrosis. Mini-invasive Surg 2020;4:14. http://dx.doi.org/10.20517/2574-1225.2019.55
\end{abstract}

Received: 5 Dec 2019 First Decision: 26 Jan 2020 Revised: 4 Feb 2020 Accepted: 18 Feb 2020 Published: 6 Mar 2020

Science Editor: Noriyoshi Sawabata Copy Editor: Jing-Wen Zhang Production Editor: Jing Yu

\begin{abstract}
Aim: Thoracic sympathectomy is indicated in patients with upper extremity hyperhidrosis. The success of dorsal thoracic sympathectomy is judged by the rates of relief of hyperhidrosis, recurrence, and compensatory hyperhidrosis. We studied robotic selective sympathectomy (RSS) directed at the division of the preganglionic and postganglionic rami without interruption of the sympathetic chain.
\end{abstract}

Methods: During RSS, the preganglionic and postganglionic sympathetic fibers and communicating rami to intercostal nerves 2,3 , and 4 are divided. The sympathetic chain is left intact.

Results: Forty-seven patients underwent RSS. RSS was performed in a staged fashion with the more symptomatic side first, followed by the contralateral side after at least four weeks. Mean operative time was $67 \pm 13$ min for unilateral RSS. There was no conversion to thoracotomy. The mean increase in ipsilateral palmar temperature was $1.2 \pm 0.3^{\circ} \mathrm{C}$. Median hospital stay was three days (range 1-4 days). Complications included transient heart block after sympathectomy on the second side in $1 / 47(2 \%)$ and transient partial Horner's syndrome which resolved in two weeks in $1 / 47$ (2\%). There was no permanent Horner's syndrome. Relief of hyperhidrosis was seen in $98 \%$ of patients. At a mean follow up of $28 \pm 6$ months, 46/47 (98\%) patients were free of sustained compensatory hyperhidrosis.

Conclusion: RSS is associated with excellent relief of hyperhidrosis and the lowest reported rate of compensatory hyperhidrosis.

cc) (7) The Author(s) 2020. Open Access This article is licensed under a Creative Commons Attribution 4.0 International License (https://creativecommons.org/licenses/by/4.0/), which permits unrestricted use sharing, adaptation, distribution and reproduction in any medium or format, for any purpose, even commercially, as long as you give appropriate credit to the original author(s) and the source, provide a link to the Creative Commons license, and indicate if changes were made.

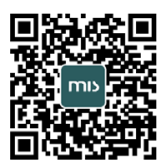


Keywords: Robotic, sympathectomy, hyperhidrosis, minimally invasive, selective sympathectomy

\section{INTRODUCTION}

Surgery on the sympathetic nervous system is characterized by the evolution of indications and techniques which have correlated with the evolution and greater understanding of the physiology and anatomy of this complex part of the nervous system ${ }^{[1-20]}$.

Presently, hyperhidrosis is the most important established indication for sympathectomy. Historically, surgical sympathectomy for hyperhidrosis has been associated with three areas of controversy: (1) the surgical approach; (2) the technique of sympathectomy; and (3) the extent of sympathectomy.

Many surgical approaches have been described: (1) the posterior thoracic approach; (2) cervical supraclavicular approach; (3) transthoracic approach; (4) trans-axillary approach; (5) thoracoscopic approach; and (6) robotic thoracoscopic approach. Sympathectomy can be accomplished by: ganglionectomy, clipping, or ablation of the dorsal sympathetic chain.

The extent of sympathectomy correlates with the incidence of complications. Clearly, more limited sympathectomy has been associated with lower rates of compensatory hyperhidrosis. Although there is no definite consensus, it has been suggested that highest success rates occur when interruption is performed for $\mathrm{T} 3$ and $\mathrm{T} 4$ for palmar hyperhidrosis. $\mathrm{T} 4$ and $\mathrm{T} 5$ interruption is recommended for palmar and axillary, palmar, axillary, and pedal hyperhidrosis. T3 interruption has been recommended for craniofacial hyperhidrosis $^{[21]}$.

Selective postganglionic sympathectomy represents a more directed approach to sympathetic denervation of the upper extremity ${ }^{[22]}$. In this procedure, the sympathetic trunk and ganglia are left intact and only the postganglionic rami, which accompany the intercostal nerves 2,3 , and 4 to the upper extremity, are divided selectively. Friedel et al. ${ }^{[23]}$ reported a success rate of up to $95 \%$ and a compensatory hyperhidrosis rate of $2.5 \%$ after performing selective postganglionic sympathectomy or ramicotomy. Recently, Coveliers and colleagues reported a series of patients who underwent robotic simultaneous bilateral selective dorsal postganglionic ramicotomy using a surgical robot ${ }^{[24,25]}$. Although postganglionic ramicotomy has been used for more than 20 years, most surgeons have abandoned the technique because studies have found a significantly higher recurrence rate in comparison with sympathectomy ${ }^{[2-29]}$. It has been suggested that the historic results with ramicotomy may have been in part due to the limitations of the visualization and instrument technology, and the fact that the preganglionic fibers were left intact.

Given the theoretical advantage of reducing compensatory sweating by limiting the extent of sympathectomy, we have reasoned that the division of both the preganglionic and postganglionic rami communicantes from the sympathetic trunk to the upper extremity without targeting the trunk itself may be a more effective technique for "selective sympathectomy".

This paper outlines the technique of robotic selective sympathectomy (RSS) and the early results.

\section{METHODS}

\section{Technique}

A left-sided double lumen tube is used and the lung on the side of the procedure is isolated. The patient is placed in a lateral decubitus position. 

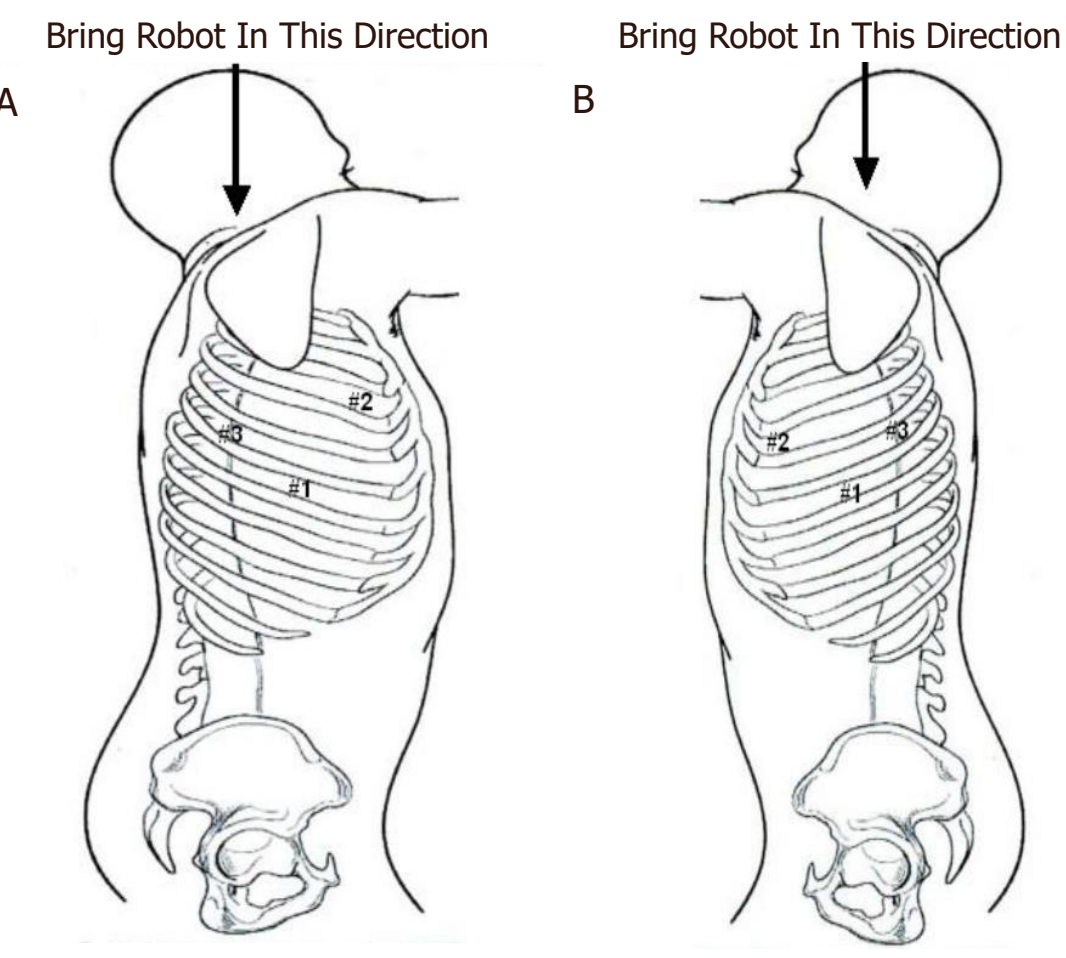

Figure 1. Port placement during robotic selective dorsal sympathectomy. A: right chest; and B: left chest

The robot is brought over the patient's head. We use both da Vinci (Intuitive Surgical Mountainview, CA) Si and Xi robots. For clarity, we refer to the robotic arms not by arm number but in reference to the surgeon's hands. An 8 -mm port (\#1) is placed in the sixth intercostal space in the midaxillary line [Figure $1 \mathrm{~A}$ and B], A second port (\#2) is placed in the third intercostal space in the anterior axillary line. The camera arm with a $30^{\circ}$ down-viewing binocular camera is introduced through Port \#1. For approach to the sympathetic chain in the right chest Port $\# 2$ is used by the right robotic arm, and for the left-sided sympathetic chain Port \#2 is used by the left robotic arm. A third port (\#3) is placed in the fifth intercostal space in the posterior axillary line. For approach to the sympathetic chain in the right chest Port \#3 is used by the left robotic arm, and for the sympathetic chain in the left chest Port \#3 is used by the right robotic arm. Carbon dioxide insufflation can be used with the port-based technique. Carbon dioxide is used to retract the lung away from the posterior chest wall. If carbon dioxide insufflation is not used, an auxiliary $10-\mathrm{mm}$ port is placed in the sixth intercostal space in the anterior axillary line. A retractor (Endopaddle Retract Covidien, Inc., Norwalk, Conn. USA) is passed through this port and used to retract the lung medially. In the right chest, the right robotic arm with the robotic hook cautery is positioned through Port \#2, and the left robotic arm with the robotic DeBakey forceps is positioned through Port \#3. In the left pleural space, the right robotic arm enters the pleural space through Port \#3 and the left robotic arm enters the pleural space through Port \#2. The sympathetic chain is identified. The ribs are counted and electrocautery marks are placed away from the sympathetic ganglia in order to specify the position of ganglia \#2, \#3, and \#4 [Figure 2]. The portion of the sympathetic chain between ganglia \#4 and $\# 5$ overlying rib $\# 5$ is identified and dissected with the hook cautery. The sympathetic chain is encircled and lifted with a rubber atraumatic vascular loop. The postganglionic fibers (RCG) can be identified easily as the fibers emanating from the chain towards the distal portion of the ribs. These fibers are divided using electrocautery. The preganglionic fibers entering the sympathetic chain are also divided and the chain is elevated. Dissection is carried to the level of the second sympathetic ganglion. Following the division of the preganglionic and postganglionic fibers, the sympathetic chain is elevated and all posterior attachments to the ribs are severed using electrocautery. This maneuver disconnects the rami interganglionares that are communicating fibers between the ganglia. 


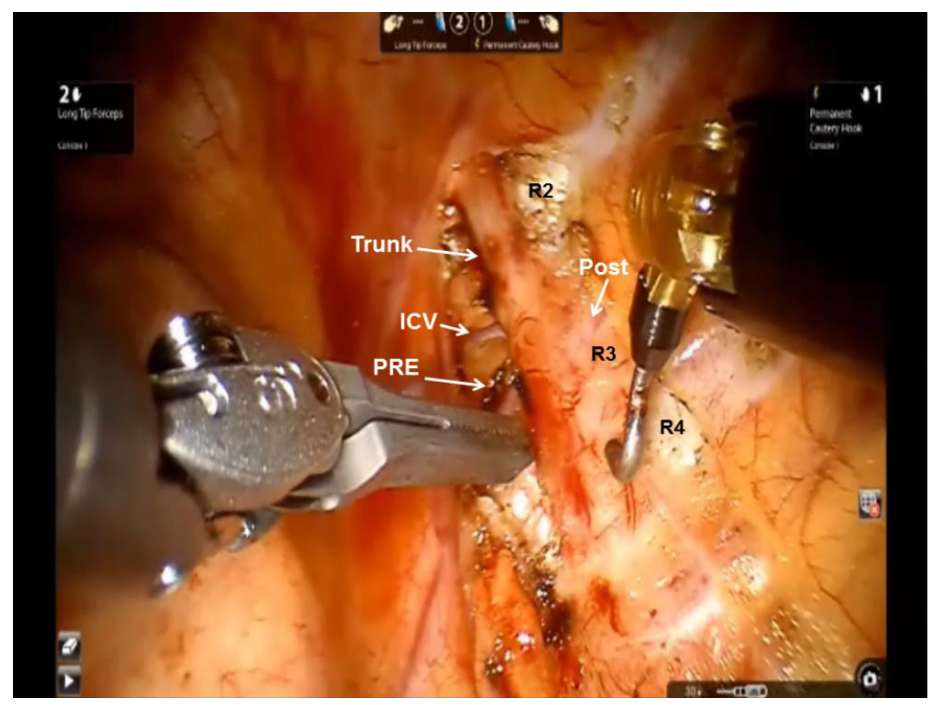

Figure 2. Intraoperative photograph during left robotic selective sympathectomy depicting Ribs 2-4 (R2, R3, and R4), the PRE and Post rami, the Trunk, and an ICV. During "selective sympathectomy" preganglionic and postganglionic rami are divided, and the trunk is left intact. PRE: preganglionic; Post: postganglionic; ICV: intercostal vein; Trunk: sympathetic trunk

Following completion of the highly selective sympathectomy, a flexible drain is positioned posteriorly in the pleural space and brought out through Incision \#1. On-Q subpleural catheters are placed traversing T2T8, as has been described elsewhere in this book for pain control. All patients are extubated and returned to the recovery room.

Video of the procedure can be seen at https://youtu.be/8NvTznv4Qrg.

All patients underwent division of R2, R3, and R4 preganglionic and postganglionic rami.

\section{Data analysis}

The data were prospectively accrued and retrospectively analyzed. Data points analyzed included indications for operation, patient age and sex, preoperative and postoperative Hyperhidrosis Disease Severity Scale [Table 1], operative time, palmar temperature measurements, morbidity, death, compensatory hyperhidrosis, and gustatory sweating.

Compensatory hyperhidrosis was defined as the presence of new sweating, which was not present preoperatively, in a different part of the body. The presence of compensatory hyperhidrosis and gustatory hyperhidrosis was based on the subjective reporting of the patient.

Relief of symptoms, satisfaction with the operation, and occurrence and intensity of compensatory sweating were evaluated using a standard questionnaire and the Hyperhidrosis Disease Severity Scale. Further follow up was conducted at three months and at one, two, and three years after the operation. At the time of follow up, relief of symptoms, satisfaction with the operation, and occurrence and intensity of compensatory sweating were evaluated using a standard questionnaire and the Hyperhidrosis Disease Severity Scale.

\section{RESULTS}

In total, 102 patients underwent RSS. In 55 patients, RSS was performed in a simultaneous bilateral fashion. In 47 patients, RSS was performed in staged fashion with the more symptomatic side first, followed by the contralateral side after at least four weeks. These patients are the subject of this study. In all patients, the 
Table 1. Hyperhidrosis disease severity scale

\begin{tabular}{ll}
\hline A & Sweating is never noticeable and never interferes with daily activities \\
B & Sweating is tolerable and sometimes interferes with daily activities \\
C & Sweating is barely tolerable and frequently interferes with daily activities \\
D & Sweating is intolerable and always interferes with daily activities \\
\hline
\end{tabular}

indication was axillary and palmar hyperhidrosis. Mean operative time was $67 \pm 13 \mathrm{~min}$ for unilateral RSS. There was no conversion to thoracotomy. The mean increase in ipsilateral palmar temperature was $1.2 \pm 0.3^{\circ} \mathrm{C}$. Median hospital stay was three days (range 1-4 days). Chest tube was removed on the first postoperative day (POD\#1) in 43/47 (92\%) patients and the second postoperative day (POD\#2) in 4/47 (8\%) patients. There were no bleeding complications. Complications included transient heart block after sympathectomy on the second side in 1/47 (2\%) and transient partial Horner's syndrome that resolved in two weeks in 1/47 (2\%). There was no permanent Horner's syndrome.

Whereas all patients had a score of D preoperatively, at a mean follow up of $28 \pm 6$ months, 46/47 patients had a score of $\mathrm{A}$. The overall sustained resolution of hyperhidrosis was $98 \%$. In one patient (2\%), hyperhidrosis recurred in the first operated side after three months.

Compensatory hyperhidrosis was seen in 19/47 (40\%) patients after selective dorsal sympathectomy of the dominant upper extremity. The contralateral selective dorsal sympathectomy was delayed until the resolution of the transient compensatory hyperhidrosis, which occurred within four weeks in all patients. Transient compensatory hyperhidrosis was seen in 21/47 (45\%) after selective dorsal sympathectomy of the contralateral upper extremity. This resolved in 46/47 patients within five weeks after the procedure. At a mean follow up of $28 \pm 6$ months, $46 / 47$ (98\%) patients were free of sustained compensatory hyperhidrosis. One patient (2\%) experienced compensatory hyperhidrosis affecting the anterior abdomen and lower chest. There was no gustatory sweating in this group of patients.

\section{DISCUSSION}

The success of dorsal thoracic sympathectomy is judged by: (1) high rate of relief of hyperhidrosis; (2) low rate of recurrence; and (3) low rate of compensatory hyperhidrosis and gustatory hyperhidrosis.

Invariably, surgical procedures achieve symptomatic relief but are associated with compensatory hyperhidrosis in $50 \%-97 \%$ of patients ${ }^{[30-33]}$. Compensatory hyperhidrosis, which occurs on the trunk and lower extremities following sympathectomy and gustatory hyperhidrosis and refers to facial sweating associated with eating or olfactory sensation of hot spicy food, is a significant complication of sympathectomy. As a result, several studies have attempted to determine whether limiting the extent of sympathectomy can impact the incidence of these two complications ${ }^{[34-40]}$. However, the results have been inconsistent and randomized trials have not been performed. In 2000, Furlan et al. ${ }^{[4]}$ reviewed published series after sympathectomy. They reported a compensatory hyperhidrosis rate of $52.3 \%$, gustatory hyperhidrosis rate of $32.3 \%$, phantom hyperhidrosis of $38.6 \%$, and Horner's syndrome in $2.4 \%$ of patients. In 2200 patients undergoing ablation of T2 ganglion for palmar sweating and T3-T4 ganglia for axillary sweating, Lin and associates showed successful sympathectomy in $99 \%$ of patients ${ }^{[42]}$. However, compensatory hyperhidrosis was noted in $88 \%$ of patients. From these studies, a number of conclusions can be reached: (1) longer extent of dorsal thoracic sympathectomy is associated with greater risk of compensatory hyperhidrosis; (2) the severity of compensatory hyperhidrosis is decreased with staging of dorsal sympathectomy with unilateral sympathectomy accomplished a few weeks apart versus bilateral sympathectomy at the same setting; (3) the extent of compensatory hyperhidrosis is decreased with selective ramicotomy; and (4) incidence of Horner's syndrome is lower with transthoracic approach when 

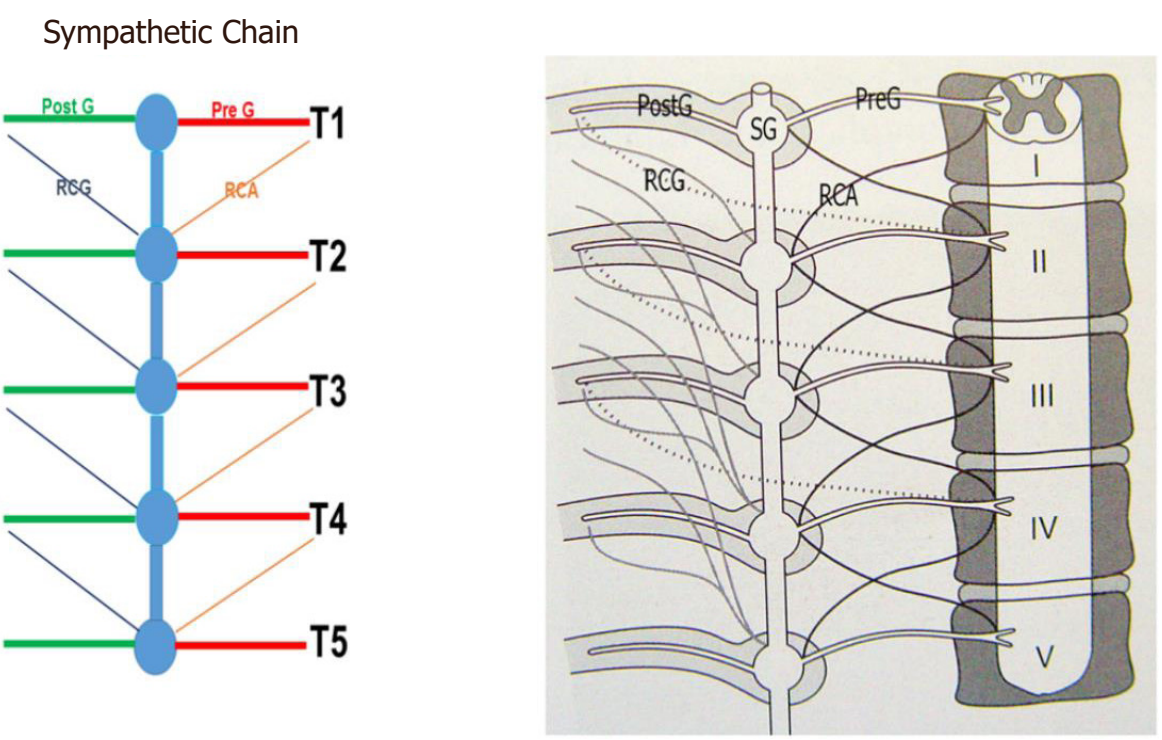

Figure 3. Sympathetic chain from $T 1$ to $T 5$. PreG fibers from the spinal cord synapse within the SG and PostG fibers travel with the intercostals nerves. The RCA connect the corresponding spinal nerves with the ganglia of the sympathetic chain. The RCG connect within the sympathetic chain with the RCA and proceed to the peripheral organs. PreG: Preganglionic; SG: sympathetic ganglion; PostG: postganglionic; RCA: rami communicantes albi; RCG: rami communicantes grisei

sympathectomy is performed by dissection versus diathermy of the T2 ganglion or when sympathectomy is limited to below the T2 ganglion.

Landmark studies by Wittmoser and later by Friedel have determined the ideal extent of sympathectomy. Friedel et al. ${ }^{[23]}$ studied three possible techniques for selective sympathectomy: (1) thoracic resection of the sympathetic chain including T2-T4 ganglia and intervening trunk. They referred to this technique as interganglionare. They concluded that this technique results in compensatory hyperhidrosis in the majority of patients. With this technique, Horner's syndrome is seen in a smaller percentage of patients compared to thermal ablation. The shortcoming of this technique is the possibility of leaving the postganglionic RCG with resultant less than complete sympathectomy [Figures 3 and 4]; (2) division of the preganglionic rami communicantes albi (RCA) [Figure 5]; and (3) division of preganglionic, and postganglionic fibers as well as RCG and RCA for T2-T4 [Figure 6].

Using the technique of selective sympathectomy with the division of the postganglionic RCG for T2T4, these authors showed relief of axillary hyperhidrosis in all of their patients. Furthermore, with this technique, they did not report any patients with Horner's syndrome. Finally, this technique has resulted in the lowest reported rate of compensatory hyperhidrosis (16\%).

It has been postulated that limiting the extent of sympathectomy or sympathicotomy may decrease the rate of compensatory hyperhidrosis. The thoracic sympathetic chain is composed of both nerve bodies of the second sympathetic neuron as well as postganglionic axons from nerve bodies from other levels that travel within the chain. Microscopic examination of what macroscopically appears as a ganglion in the sympathetic chain reveals a combination of nerve bodies as well as communicating axons from other nerve bodies that travel up and down the chain. Based on this understanding, division of a single macroscopic ganglion does not result solely in the removal of the nerve bodies to that specific level, but also results in the division of the axons from nerve bodies from other levels which travel through the chain. This realization may explain the variability of the extent of sympathectomy when the chain is divided or specific macroscopic ganglia are removed. 

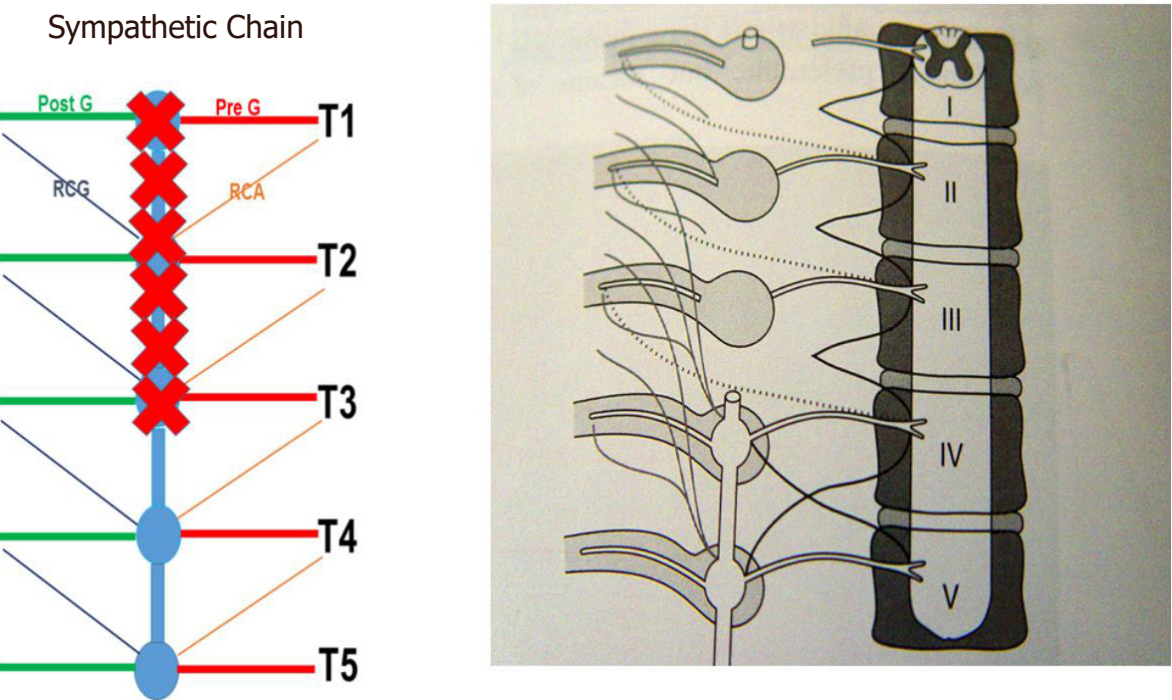

Figure 4. Classic gangliectomy sympathectomy. PreG: Preganglionic; PostG: postganglionic; RCA: rami communicantes albi; RCG: rami communicantes grisei

\section{Sympathetic Chain}
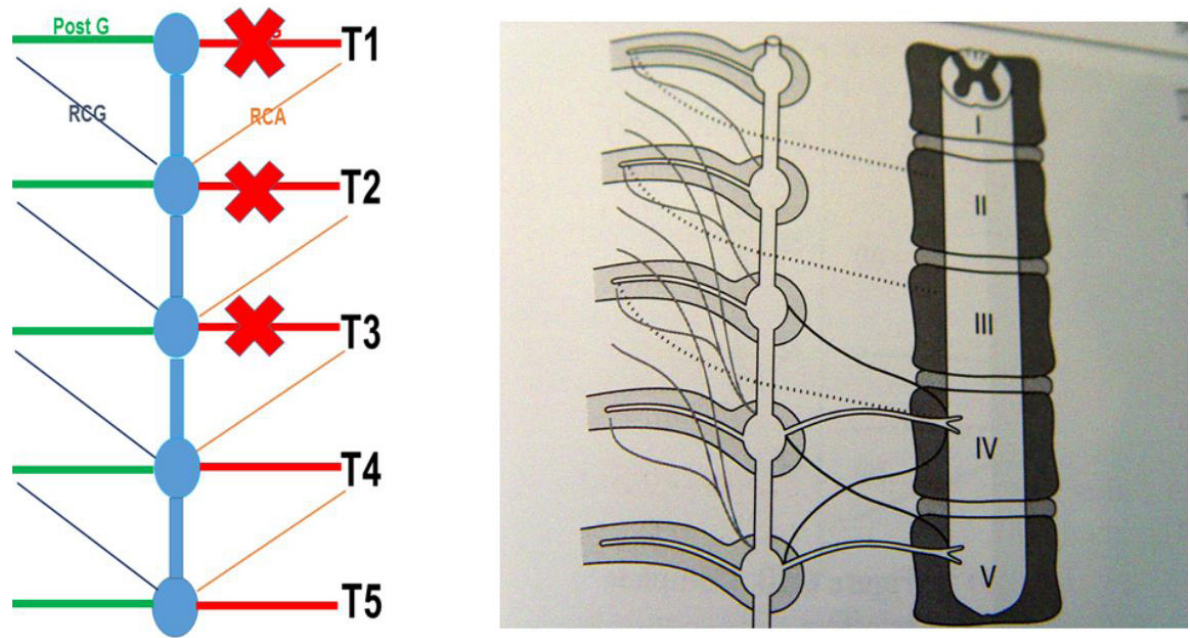

Figure 5. Preganglionic sympathectomy. PreG: Preganglionic; PostG: postganglionic; RCA: rami communicantes albi; RCG: rami communicantes grisei

Selective postganglionic sympathectomy represents a more directed approach to sympathetic denervation of the upper extremity. In this procedure, the sympathetic trunk and ganglia are left intact and only the rami that accompany the intercostal nerves 2,3 , and 4 to the upper extremity are divided selectively.

Friedel et al. ${ }^{[23]}$ reported a success rate of up to $95 \%$ and a compensatory hyperhidrosis rate of $2.5 \%$ after performing selective postganglionic sympathectomy or ramicotomy by thoracotomy. However, subsequent studies with longer follow up showed that the results were transient and that the long-term compensatory hyperhidrosis rate with this technique was $60 \%-70 \%$, comparable to other techniques. It has been suggested that the lack of sustained results with this technique was the result of poor visualization of the rami, incomplete ramicotomy, and division of only the postganglionic rami. 
Sympathetic Chain

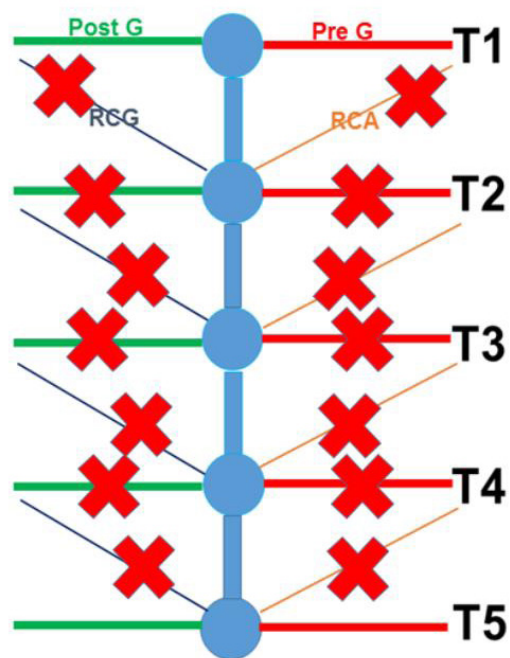

Selective Dorsal Sympathectomy

Transection of T2, T3, T4, PreG, Post G, RCA, RCG

Figure 6. Selective dorsal sympathectomy with division of both preganglionic and postganglionic rami. PreG: Preganglionic; PostG: postganglionic; RCA: rami communicantes albi; RCG: rami communicantes grisei

Selective sympathectomy is not easily accomplished with conventional video-assisted thoracic surgical techniques. The improved dexterity and three-dimensional visualization used with robotic technology makes robotics ideal for selective dorsal thoracic sympathectomy. Using robotic technology and taking advantage of the three-dimensional high resolution magnified view and improved instrument maneuverability in the confined space, Coveliers et al.$^{[2,25]}$ reported a series of patients who underwent simultaneous bilateral selective dorsal postganglionic sympathectomy who after a two-year follow up had a $96 \%$ rate of relief of hyperhidrosis and a $7.2 \%$ rate of compensatory sweating.

Given the theoretical advantage of reducing compensatory sweating by limiting the extent of sympathectomy, we have reasoned that the division of both the preganglionic and postganglionic rami communicantes from the sympathetic trunk to the upper extremity without targeting the trunk itself may be a more effective technique for "selective sympathectomy". Furthermore, as compensatory hyperhidrosis after sympathectomy is believed to result from redirection of sympathetic activity to other parts of the body, and has been shown to be related to the extent of sympathectomy, staged bilateral robotic sympathectomy of one upper extremity followed by the other may result in even lower levels of compensatory hyperhidrosis.

In this study, patients with combined axillary and palmar hyperhidrosis underwent RSS in a staged fashion. The staged approach was chosen to allow for the transient compensatory hyperhidrosis to dissipate before further interruption of the sympathetic flow. In addition, given the morbidity associated with the robotic ports, a staged bilateral approach was chosen to obviate bilateral thoracic pain. Presumably due to the use of three robotic ports, optimal pain management necessitated longer hospital stay.

The use of robotic technology adds more ports and results in greater morbidity, longer operative times, and greater cost. These shortcomings may be offset by greater accuracy of dissection and lower rates of compensatory hyperhidrosis. 
A randomized, prospective trial comparing this approach with other conventional approaches needs to be performed to further validate the results.

In conclusion, robotic technology has the potential of accomplishing highly selective dorsal preganglionic and postganglionic sympathectomy with accuracy. This technique may decrease the incidence of post sympathectomy compensatory hyperhidrosis and Horner's syndrome.

\section{DECLARATIONS}

\section{Authors' contributions}

The author contributed solely to the article.

\section{Availability of data and materials}

Not applicable.

\section{Financial support and sponsorship}

None.

\section{Conflicts of interest}

The author declared that there are no conflicts of interest.

\section{Ethical approval and consent to participate}

Not applicable.

\section{Consent for publication}

Not applicable.

\section{Copyright}

(c) The Author(s) 2020.

\section{REFERENCES}

1. Royle JP. History of Sympathectomy. Aust N Z J Surg 1999;69:302-7.

2. Gaskell WH. The involuntary nervous system. Longman: Green and Co., London; 1920.

3. Bernard C. Sur les effets de la section de la portion cephalous du grand sympathique. CR Soc Biol 1852;4:168-70.

4. Brown-Sequard CE. Experimental researches applied to physiology and pathology. New York: Forgotten books; 1853.

5. Alexander W. The treatment of epilepsy. Edinburgh: Nabupress; 1889. pp. 228.

6. Jonnesco T. Resecta totala si bilaterala a simpaticulu cervical in cazuri de epilepsie si gusa exophthalmia. Romania Med 1896;4:479-96.

7. Jaboulay M. Chirugie du grand sympathique et corps thyroide (Les different goiters). Lyons, France: Storck \& Cie, Lyons, 1900. (in French)

8. Francois-Frank CA. Signification ohysiologique de la resection du sympathique dans la maladie de Basedow, l'epilepsie, l'idiotie etle glaucoma. Bull Acad Med Paris 1899;41:565-94.

9. Jonnesco T. Angine de poi trine guerie par le resection du sympathique cervicothoracique. Bull Acad Med Paris 1920;84:93-102.

10. Leriche R. De elongation et de la section des nerfs perivasculaires dans certain syndrome douloureux d'origine arterielle et dans quelque troubles trophique. Lyon Chir 1913;10:378-82.

11. Bruning F. Zur technik der kombinierten resectionsmethode samtlicher sympathischen nervenbahnen am hasle. Zentralbl Chir 1923;5:1056-9.

12. Kotzareff A. Resection partielle du tronc sympathique cervical droit pour hyperhidrose unilaterale. Rev Med Suisse Rom 1920;40:111-3.

13. Royle ND. A new operative procedure in the treatment of spastic paralysis and its experimental basis. Med J Aust 1924;1:77-86.

14. Diez J. Un Nuevo methdo de simpatectomia periferica para el tratamiento de las afecciones troficas y gangrenosas de los miembros. Bol Soc Cir B Aires 1924;8:792-806.

15. Adson AW, Brown GE. Treatment of Raynaud's disease by lumbar ram section and ganglionectomy's and per vascular sympathetique neurectomy of the common iliacs. JAMA 1925;84:1908-10.

16. Hughes J. Endothoracic sympathectomy. Proc R Soc Med 1942;35:585-6. 
17. Kux M. Thoracic endoscopes sympathectomy in palmar and axillary hyperhydrosis. Arch Surg 1978;113:264-6.

18. Wittmoser R. Toracoscopic Sympathectomy and agronomy. In: Cuschieri A, Buess G, Périssat J, editors. Operative manual of endoscopes surgery. Berlin: Sringer Verlag; 1992.

19. Schurr MO, Buess G. Wittmoser's technique of thoracoscopic sympathectomy and agronomy. Endosc Surg Allied Technol 1993;1:266-70.

20. Friedel G, Linder A, Toomes H. Sympathectomy and agronomy. In: Mannke K, Rosin RD, editors. Minimal access thoracic surgery. London: Chapman Hall; 1998. pp. 67-83.

21. Cerfolio RJ, De Campos JR, Bryant AS, Connery CP, Miller DL, et al. The Society of Thoracic Surgeons expert consensus for the surgical treatment of hyperhidrosis. Ann Thorac Surg 2011;91:1642-8.

22. Lee DY, Kim DH, Paik HC. Selective division of T3 rami comunicantes (T3 ramicotorny) in the treatment of palmar hyperhidrosis. Ann Thorac Surg 2004;78:1052-5.

23. Friedel G, Linder A, Toomes H. Selective video-assisted thoracoscopic sympathectomy. Thorac Cardiovasc Surg 1993;41:245-8.

24. Coveliers H, Meyer M, Gharagozloo F, Wisselink W, Rauwerda J, et al. Robotic Selective Postganglionic Thoracic Sympathectomy for the treatment of hyperhidrosis. Ann Thorac Surg 2013;95:269-74.

25. Coveliers H, Meyer M, Gharagozloo F, Wisselink W. Selective Sympathectomy for hyperhidrosis: technique of robotic transthoracic selective postganglionic sympathectomy. Eur J Cardiovasc Surg 2013;43:428-30.

26. Gossot D, Toledo L, Fritsch S, Célérier M. Thoracoscopic sympathectomy for upper limb hyperhidrosis: looking for the right operation. Ann Thorac Surg 1997;64:975-8.

27. Kim DH, Paik HC, Lee DY. Comparative analysis of T2 selective division of rami-communicantes (ramicotomy) with T2 sympathetic clipping in the treatment of craniofacial hyperhidrosis. Eur J Cardiothorac Surg 2004;26:396-400.

28. Lee DY, Paik HC, Kim DH, Kim HW. Comparative analysis of T3 selective division of rami communicantes (ramicotomy) to T3 sympathetic clipping in treatment of palmar hyperhidrosis. Clin Auton Res 2003;13:145-7.

29. Lee DY, Kim DH, Paik HC. Selective division of T3 rami communicantes (T3 ramicotomy) in the treatment of palmar hyperhidrosis. Ann Thorac Surg 2004;78:1052-5.

30. Riet M, Smet AA, Kuiken H, Kazemier G, Bonjer HJ. Prevention of compensatory hyperhydrosis after thoracoscopic sympathectomy for hyperhydrosis. Surg Endosc 2001;15:1159-62.

31. Neumayer C, Zacherl J, Holak G, Függer R, Jakesz R, et al. Limited endoscopes thoracic sympathetic block for hyperhydrosis of the upper limb: reduction of compensatory sweating by clipping T4. Surg Endosc 2004;18:152-6.

32. Lin TS. Endoscopic clipping in video-assisted sympathetic blocade for axillary hyperhydrosis. An analysis of 26 cases. Surg Endosc 2001;15:126-8.

33. Lin CC, Telaranta T. Lin-telaranta classification: the importance of different procedures for different indications in sympathetic surgery. Ann Chir Gynaecol 2001;90:161-6.

34. Schmidt J, Bechara FG, Altmeyer P, Zirngibl H. Endoscopic thoracic sympathectomy for severe hyperhydrosis: impact of restrictive denervation on compensatory hyperhydrosis. Ann Thorac Surg 2006;81:1048-55.

35. Gossot D, Toledo L, Fritsch S, Célérier M. Thoracoscopic sympathectomy for upper limb hyperhydrosis: looking for the right operation. Ann Thorac Surg 1997;64:975-8.

36. Doolbah N, Horswell S, Williams M, Huber L, Prince S, et al. Thoracoscopic sypathectomy for hyperhydrosis: indications and results. Ann Thorac Surg 2004;77:410-4.

37. Licht PB, Pilegaard HK. Gustatory side effects after thoracoscopic sympathectomy. Ann Thorac Surg 2006;81:1043-7.

38. Licht PB, Jørgensen OD, Ladegaard L, Pilegaard HK. Thoracoscopic sympathectomy for axillary hyperhydrsis: the influence of T4. Ann Thorac Surg 2005;80:455-9.

39. Kwong KF, Cooper LB, Bennett LA, Burrows W, Gamliel Z, et al. Clinical experience in 379 consecutive thoracoscopic sympathectomies. Ann Thorac surg 2005;80:1063-6.

40. Baumgartner FJ, Toh Y. Severe hyperhydrosis: clinical features and current thoracoscopic surgical management. Ann Thorac Surg $2003 ; 76: 1878-83$

41. Furlan AD, Mailis A, Papagapiou M. Are we paying a high price for surgical sympathectomy? A systematic literature review of late complications. J Pain 2000;1:245-57.

42. Lin CC, Telaranta T. Lin-Telaranta classification: the importance of different procedures for different indications in sympathetic surgery. Ann Chir Gynaecol 2001;90:161-6. 